\title{
Demand Response experience in Europe: policies, programmes and implementation
}

\author{
Jacopo Torriti*, Mohamed G. Hassan, Mathew Leach \\ Centre for Environmental Strategy, University of Surrey, Guildford, GU2 7XH, \\ United Kingdom
}

\begin{abstract}
Over the last few years, load growth, increases in intermittent generation, declining technology costs and increasing recognition of the importance of customer behaviour in energy markets have brought about a change in the focus of Demand Response in Europe. The long standing programmes involving large industries, through interruptible tariffs and time of day pricing, have been increasingly complemented by programmes aimed at commercial and residential customer groups. Developments in Demand Response vary substantially across Europe reflecting national conditions and triggered by different sets of policies, programmes and implementation schemes. This paper examines experiences within European countries as well as at European Union (EU) level, with the aim of understanding which factors have facilitated or impeded advances in Demand Response. It describes the initiatives, what is known about the technical and economic potentials, and the policies of various European countries, with in-depth case studies of the United Kingdom, Italy and Spain. It is concluded that while business programmes, technical and economic potentials vary across Europe, there are common reasons as to why coordinated Demand Response policies have been slow to emerge. This is because of the limited knowledge that has been developed about DR energy saving capacities; the high cost estimates for DR technologies and infrastructures; and the policy-makers focus on creating the conditions for liberalising the EU energy markets.
\end{abstract}

\section{KEYWORDS}

Demand Response; European Union; market liberalisation; smart meter. 


\section{INTRODUCTION}

Demand Response (DR) refers to a wide range of actions which can be taken at the customer side of the electricity meter in response to particular conditions within the electricity system (such as peak period network congestion or high prices). Leach et al explore the diversity of timescales, types of signal and involvement of customers in different types of demand side action [1]. That paper demonstrates a spectrum of actions, sharing common influences, but also draws some clear differences between actions taken to effect long term improvement in the efficiency with which energy services are delivered and actions taken to meet shorter term needs, such as peak load shifting. Within several European countries there are long standing arrangements or programmes to harness the largest and most energy intensive industrial customers in DR, through interruptible tariffs or time of day pricing, and some system operators make use of large avoided loads as part of their system balancing activities. Reflecting rising challenges from load growth, ambitions for deeper uptake of "intermittent" generation, technological developments in low cost power electronics and IT and generally growing recognition of the importance of customer "behaviour", there is increasing interest in Europe in DR opportunities more widely, across smaller commercial and residential customer groups.

In principle DR initiatives can bring about significant reductions in electricity prices, as shifts of demand during peaks could reduce the need for higher marginal cost generation, offer lower cost system balancing and decrease grid reinforcement investment [2]. DR initiatives can also play a valuable role in achieving ambitious environmental policy objectives, through facilitating greater connection of intermittent renewable generation. In practice, however, markets do not always respond as they should and there are obstacles that prevent full implementation of DR in the market. The main obstacles to DR are recognised to be the inelasticity of demand and low level of participation due to asymmetries in information. The literature dedicates significant attention to these two broad problems, underlying, on the one hand, the difficulties of flattening the demand curve for electricity due to lack of policies aimed at designing Time of Use tariffs that will produce the greatest shifts in usage [3, 4] and slow deployment of the technical infrastructures, e.g. smart metering, necessary to facilitate demand-side participation [5]. 
In addition to these two broad obstacles, there are other factors, specific to the European context, which have played a crucial role in preventing market penetration of DR. Examining these factors is vital not only in order to appreciate what has prevented significant implementation of DR to date, but also to explore possible future developments in Demand-Side Management and demand-side participation in Europe.

An accurate picture of DR in Europe needs to take into account various aspects: (i) the DR initiatives and programs which have been undertaken in the last five years; (ii) the estimates that have been derived on the technical and economic potential of DR in Europe, as well as the factors which are preventing the full exploitation of such potential; and (iii) the policies which have been put forward in order to foster DR initiatives.

This paper examines DR experiences within European countries as well as at EU level with the aim of understanding what has favoured or hampered the development of DR in Europe. It introduces the factors instrumental in facilitating or hindering market penetration of DR in European electricity markets (section 2). It defines the economic and technical potential for DR in the European Union, and describes the evolution of EU policies on DR (section 3). It presents an overview of DR initiatives in various European countries; reviews the studies carried out at national level on DR; examines in depth the DR initiatives, DR potential and DR policies of three European countries: UK, Italy and Spain (section 4). It discusses the factors presented in section 2 against findings from EU and national levels (section 5).

\section{FACTORS SHAPING DR IN EUROPEAN ELECTRICITY MARKETS}

\subsection{European Electricity Markets}

European Parliament and Council Directives led to liberalisation in EU energy markets [6]. The directives lay down the general conditions required for the creation of a single Internal Electricity Market (IEM) in Europe, but avoided specifying a single market model. Instead the EU gave its Member States the freedom to design their markets and regulatory frameworks to suit national conditions, so long as 
broader objectives - such as open and fair third party access to national markets and introduction of competition - were adopted. One of the aims was to offer end-users choice between suppliers so that they can benefit from lower prices for energy and a better quality of service.

The EU Treaties of Rome (1957) and Maastricht (1993) laid the foundation for the creation of an internal market in the European Union with free movement of people, goods, and capital. In the past, supply of electricity was considered a service of general economic interest and consequently not subject to the normal rules of competition as established by the EU treaties. The European Court of Justice ruled on several occasions that electricity is a good, putting an end to the consideration of electricity as a public service. The liberalization process established by directives 96/92/EC and 98/30/EG led to the unbundling of activities. Because of the separate legal treatment of the commodity electricity (that is, the good) and the supply of electricity - that is the services which include the utility aspects as well as reliability of supply- electricity in Europe must be treated as having both characteristics of a commodity and of a service [7].

Today the European power market is a corporation of regional markets, most of which are physically inter-connected. Technical standards and market rules vary, but in most cases the barriers to trade in electricity across the borders have been lifted. The EU$27^{1}$ consumed 2.7 million GWh of electricity in 2007 and traded 6.3 million GWh in the same year.

The rapid move to restructuring and privatization of energy markets in many parts of Europe since the late 1980s has probably had a mixed effect on the fortunes of demand side activity, including DR. The architects of most market systems have explicitly designed in mechanisms by which demand side bidding for decreases in consumption can compete with generation, thus at least in principle placing DR on an even, competitive basis. However, the move away from integrated planning via staterun institutions towards private sector decision making and investment seems to have

\footnotetext{
${ }^{1}$ The European Union consist of the following Member States: Austria, Belgium, Bulgaria, Cyprus, the Czech Republic, Denmark, Estonia, Finland, France, Germany, Greece, Hungary, Ireland, Italy, Latvia, Lithuania, Luxembourg, Malta, the Netherlands, Poland, Portugal, Romania, Slovakia, Slovenia, Spain, Sweden, and the United Kingdom.
} 
favoured more traditional supply side investments as the route to keep pace with economic growth and rising electricity service demands. The energy efficiency literature is rich with evidence and analysis of why this is often the case, with higher transaction costs in accessing numerous smaller opportunities compared to single large investments one key aspect.

\section{DEMAND RESPONSE ACTIVITY AT THE EUROPEAN UNION LEVEL}

\subsection{DR programmes}

It would be inappropriate to speak of harmonised EU-wide DR programmes. Some related initiatives are in place with regards to renewable energy technologies, labelling programmes and energy-efficient systems. In addition, there are numerous DR programmes and initiatives at Member States level, as described in section 4, but not a single DR initiative for the internal market as a whole.

A simple explanation for the absence of EU initiatives on DR is the actual inexistence of a single European energy market. The difficulties in finding arrangements for setting up the very basic structure of the internal market emerged with the discussions around the "third legislative package" for liberalising EU energy markets. The package entails a set of measures aimed at ensuring "the effective separation between the operation of electricity and gas transmission networks from supply and generation activities" [8]. To achieve effective separation, the Commission proposed two main policy alternatives (i) "ownership unbundling", i.e. the separation of powers in companies that control both energy generation and transmission, and (ii) the introduction of Independent System Operators (ISO), under which companies involved in energy production and supply would be allowed to retain their network assets, but they would not manage commercial and investment decisions, which would be left to an independent company - the ISO - to be designated by national governments. Divergences between the European Commission and a number of Member States, including France and Germany, which opposed the Commission's initiative towards "ownership unbundling" meant that this legislative package has not been approved yet [9]. Notwithstanding the absence of any harmonised DR programmes, there are studies investigating the technical and economic potential of 
demand response participation, as well as a number of EU policies linked with DR, which are worth looking at.

\subsection{DR potential in the $E U$}

With final annual electricity consumption across the main EU- $15^{2}$ Member States increasing by $2.1 \%$ in recent years [10], and with an increase of $1.5 \%$ forecasted for EU-27 by 2020 [11], additional measures aiming at the rationalisation of the use of electricity seem necessary, besides the ones already in place (e.g. renewable energy technologies, labelling programmes and energy-efficient systems). Preoccupations around the expected increase in demand have fed much recent debate on security of supply in Europe. However, from a strict market perspective, the effects of the increase of electricity demand have been so far mitigated by the still positive importexport ratio in most European countries [12].

Awareness of these aggregate figures might justify the belayed EU intervention on DR initiatives. At the same time, studies and forecasting projects have been launched to understand the full technical and economic potential of DR.

One attempt has been made by the IEA programme, Task XII. This study observes that although the implementation of smart meters is taking a long time, some European utilities along with telecommunication companies have been developing smart energy boxes that allow customers to (i) plan the use of electric appliances; (ii) manage directly several domestic appliances at the same time; (iii) manage decentralised generation facilities. Smart energy boxes can replace meters because they are provided with data loggers capable of reading on the old meters and reporting on the boxes. However, an integrated plan for smart energy boxes has not been developed yet due to the perceived excessive costs.

Other technologies developed in recent years -and still being developed- might exploit the full potential of DR in Europe. Intelligent electric consumption control strategies, for instance, can lead to significant energy and cost savings in various energy-consuming segments across Europe (e.g. public lighting, tertiary sector

\footnotetext{
${ }^{2}$ EU-15 Member States include: Austria, Belgium, Denmark, Finland, France, Germany, Greece, Ireland, Italy, Luxembourg, the Netherlands, Portugal, Spain, Sweden and the United Kingdom.
} 
buildings, residential buildings and industry). These intelligent devices can be associated with either Demand Side Management (DSM) or DR programmes, depending on the duration of their effects. The duration of their impacts is also strictly related to market penetration. To a high market penetration would correspond a higher probability of long-term economic impacts of intelligent devices on the market. A recent study estimated that, under the hypothesis of high market penetration, the EU15 area would experience a reduction of between $1 \%$ and $4 \%$ in primary energy, between $1.5 \%$ and $5 \%$ in $\mathrm{CO}_{2}$ emissions and between $2 \%$ and $8 \%$ saving in investment costs for power generation expansion [13]. In summary, technological progress in some European countries is providing the tools necessary to allow DR, by allowing customers to react to and participate in the electric market. As technology and innovation further develop, greater opportunities for demand responsiveness grow in the marketplace, as is explained in depth for individual countries in Section 4.

The broad economic and environmental potentials of DR for the EU have also been assessed under scenario analysis in a recent study carried out by Capgemini [14]. Under the most moderate scenario, which takes into account that the implementation of devices such as smart meters in Europe is rather slow, EU-wide benefits of DR by 2020 would comprise 100 TWh of annual energy saving; an annual reduction of 30 million tons of $\mathrm{CO} 2$; and tens of billions of Euros both in terms of savings in avoided investment relating to peak generation capacity and Transmission \& Distribution, and savings for customers in electricity bills.

Other studies investigating the economic potential of DR in Europe have focused mainly on individual countries, looking at pilot studies in order to understand the broader economic potential associated with DR activities. While these studies estimate different levels of peak reductions in different European countries thanks to DR, a recent study by UCTE, the European association of Transmission System Operators (TSOs) provides forecasts for DR in European countries [22]. The UCTE study defines the level of DR in European countries in 2008 at on average $2.9 \%$ of peak load. Table 1 shows that DR is foreseen to grow in most UCTE countries with the only exceptions of Germany and Hungary. These projections for the future are not likely to revolutionise the 2008 baseline. 
Table 1-Demand Response forecast in UCTE countries (GW)

Studies on the economic and technical potential of DR vary significantly in methods, sample sizes and results. However, at least four significant observations can be derived from this brief review. First, the total amount of DR, as analysed in system adequacy studies, is rather low and flat in recent years. Second, in continental Europe, load management forecasts increased during recent years. Third, studies confirm that most existing DR initiatives consist of interruptible programmes. Fourth, a significant number of European countries do not even consider DR in system and network planning.

\subsection{EU policies on DR}

Although the EU does not envisage any harmonised DR policy, there are two EU directives which address DR issues.

The Energy Services Directive requires Member States to develop plans for achieving targets for saving energy from end users but the wording of the Directive is being left broad, such that it can encompass DR options and technologies as well as demand saving measures: "In defining energy efficiency improvement measures, account should be taken of efficiency gains obtained through the widespread use of costeffective technological innovations" [15]. Ultimately, this Directive does not require DR programmes. While Member States could interpret DR programmes, such as time-of-use tariffs, as a contribution to meeting the requirements of the Directive, the main focus of the directive is on energy efficiency.

Another Directive, on Energy End-Use Efficiency and Energy Services suggests that Member States should promote "the adoption of real-time demand management technologies such as advanced metering systems" [16]. This Directive is intended to provide incentives for investment in transmission and distribution networks while the European market gradually opens up to competition. In order to address the risk of interruptions caused by increases both in power demand and strains on the network, the Directive proposed four main requirements: (i) Member States should have a clearly defined policy to ensure a good equilibrium between power supply and 
demand; (ii) Member States should define and meet standards concerning the security of transmission and distribution networks (with financial penalties being foreseen in case of failure to comply with the targets); (iii) TSOs should submit regular investment plans for cross-border interconnectors to their national regulators; and (iv) national regulators should submit a summary of these investment plans to the European Commission for consultation with the European Regulators Group on Electricity and Gas.

A recent Communication from the European Commission recognises the importance of DR, although still with a primary focus on efficiency: "Member States can encourage energy savings in all sectors by raising awareness of the need of taking action and the practical possibilities available. The Directive ${ }^{1}$ requires Member States to ensure that information on energy efficiency mechanisms and financial legal frameworks is transparent and widely disseminated to relevant market actors. They should ensure that information on best energy savings practices is widely available. Such information coupled with clear price signals, tariffs encouraging energy efficiency and better feed-back on annual consumption, through improved billing and smart meters, should put end-users in a position to take better-informed decisions on their energy use and on taking up efficiency incentives" [17].

Clearly EU energy policies are more focused on energy efficiency and DSM issues, rather than DR. One reason stems from the historical driving forces for EU energy and environment policy action. Energy efficiency and renewables programmes were developed historically and pursued vigorously since the oil shocks of the 1970s and 1980s. They have been actively pursued in recent years as part of climate change actions within the EU. Interest in DR has grown only more recently for the reasons discussed earlier. One further explanation for why the EU is not really getting involved in DR policies is that it does not have an adequate system in place to monitor the market. In Europe the thinking seems to prevail that DR is a market instrument that might be (and indeed has proved to be in certain sectors) effective in reducing the costs of load peaks for the system, but yet is not seen as a key solution for addressing the environmental objectives and climate change targets agreed across Member States. However, there is growing recognition that DR may be an effective facilitator 
of deeper penetration of renewable generation, and thus with an integral part to play in climate action [18].

\section{DEMAND RESPONSE EXPERIENCES IN EUROPEAN COUNTRIES}

The market designs and policies in place in several European countries have not promoted innovations or opportunities for DR in electricity markets. Some of the DR programmes in place in EU Member States have thus far focused on large industrial users - as will be demonstrated for Spain and Italy - and represent poor substitutes for the benefits possible from a more comprehensive approach to DR, inclusive of informed shedding operated by commercial and household consumers. This section is arranged in two parts. The first part consists of a brief overview of the range of DR programmes in place in various European countries. The second part examines in depth the programmes, technical and economic studies and policies of three countries: UK, Italy and Spain.

\subsection{DR programmes in European countries: an overview}

Over the past 20 years, European utilities have used various forms of load shedding mechanisms with large industrial customers to reduce demand during peak periods. These programmes are typically not based on accurate price signals that serve as the basis for dynamic pricing options. They are less costly to adopt and are based on discrete timing and pricing of interruption. For example, in Sweden a temporary law for peak power reserves was in place between 2003 and 2008. It was based on studies on DR which showed that most Swedish industries would be able to face reductions between 30 minutes and 3 hours per day. The law was established by the Swedish Government in order to secure enough reserve -and peaking- capacity [19]. Auctions were arranged for reserve capacity up to $2000 \mathrm{MW}$. After the temporary law period, an evaluation was carried out on how the market participants used their intervals to pave the way for a market-based solution.

Similarly to what occurred in Sweden, in Finland Interruptible Programmes have been used as disturbance reserve for several years. Companies have yearly contracts with the national electricity transmission grid operator (Fingrid). In 2005, total DR 
potential in Finnish large-scale industry was estimated at about $1280 \mathrm{MW}$, which represents 9\% of the Finnish power demand peak [20]. In 2008 the Finnish main electricity utility invested in an Advance Metering Reading system to automatically read, control and manage all 60,000 of its customer metering points.

In the Netherlands the Ministry of Economic Affairs has estimated the potential for Load Management directly related to market prices with a capacity of about 1000$1500 \mathrm{MW}$. This figure is supposed to increase gradually over the period until 2020 and is based on the bid system for reserve and regulation power of the Dutch TSO [21].

These are examples of long standing arrangements to employ the largest and most energy intensive industrial customers in DR. Recent developments have re-shaped DR in various countries, with increasing focus on programmes requiring deliberate and informed demand decisions by commercial and residential customers.

A typical example of a programme making use of different prices according to the weather is Electricité de France's Tempo tariff [22]. Around 350,000 residential customers and more than 100,000 small business customers use the Tempo tariff. Days are distinguished according to price using a colour system, together with an indication of whether the hour is currently one of eight off-peak hours or not. Customers can adjust their consumption either manually or by selecting a programme for automatic connection and disconnection of separate water and space-heating circuits. It has been estimated that for the average $1 \mathrm{~kW}$ French house, the Tempo tariff brought about a reduction in consumption of $15 \%$ on "white" days and $45 \%$ on "red" days [23]. This means that customers have saved $10 \%$ on average on their electricity bill. In addition, RTE estimates that the effect of Direct Load Management might save about 35 TWh per year by 2020 .

A Danish study estimated the benefits that DR contracts could bring about to residential users. Some $260 \mathrm{MW}$ would be saved on a typical winter day, equivalent to $6 \%$ of the Danish peak load $(6,400 \mathrm{MW})$ if $50 \%$ of the 125,000 households with electric heating in Denmark were to accept DR contracts. The pilot study was carried out on 25 houses and showed that it is possible to obtain DR impacts of up to $5 \mathrm{~kW}$ 
per household [24]. Following this case study, the Danish TSO supported a research project concerning frequency-controlled equipment in households and businesses. The main electricity company (NESA) has started installing 110,000 metering system annually to serve all 550,000 customers within 5 to 6 years.

In Norway specific programmes have been undertaken with the objectives of postponing expansion of grid capacity: $10 \%$ reduction in peak demand in the Oslo area; increasing knowledge of customer behaviour; and developing a motivation model for DSM. Pilot studies show that thanks to this DR programme the peak load for commercial end-users was reduced by 4.5 MW and the energy saving was around $15 \%$.

\subsection{United Kingdom (UK)}

\subsubsection{DR programmes in the UK}

Levels of consumption and liberalisation of the energy markets are vital elements for understanding the state of DR in the UK. Household energy consumption in the UK increased by $19 \%$ between 1990 and 2000 and energy use by appliances went up $9 \%$. Since 1990 the number of households increased by $10 \%$; population increased by 4\%; and disposable income increased by 30\% [25]. In 2002 the energy regulator, Ofgem, decided to remove price control as these were believed to be harming the competitive market [26].

Specific DR programmes have been in place for some years. In the industrial and large commercial sectors, energy intensive users are able to agree Time of Use and/or interruptible contracts with suppliers. Similarly, the System Operator can contract such large users directly as part of their network balancing activities. At the other end of the scale, it is estimated that about 4.5 million UK customer make use of multi-rate energy tariffs. This involves programmes providing customers with the option to obtain discounted electricity rates at night. "Economy 7" is one example of these Time of Use programmes: typically from 01:00 to 08:00 in the morning cheaper tariffs are applied so that customers using electrically charged thermal storage heaters can meet their space heating needs from off-peak electricity. In order to participate in these programmes, customers need two-register meters, which most of the time consist of radio and tele-switched meters installed by their distribution network 
operator or supplier. Such electrical storage heating was particularly successful in the UK as a complement to the nuclear power programme from the 1960's. The requirement for nuclear generators to operate continuously caused the then stateowned system operator to incentivise load shifting to provide a higher and stable night time baseload, and since liberalization in the 1990s has contributed to low baseload and off peak prices. Some of the UK's large electricity suppliers have recently restarted advertising such tariff arrangements, seeking new residential customers, perhaps in preparation for anticipated expansion of intermittent renewables and new investment in nuclear power.

\subsubsection{Estimating DR potential in the UK}

In the UK, more than in most other European countries, the diffusion of DR technologies is noticeable thanks to the range of devices on the market. Penetration in the future is likely to be high with various forms of smart meters, "dumb" meters with smart boxes, and clip-on display units.

In order to understand the long term effects on customer response of enhanced feedback on energy use, in 2007 the British Government initiated the so-called "Energy Demand Research Project". More than 10,000 households have taken part in some form of billing trial. Ofgem coordinates this trial project which is operated by consortia led by four different energy companies: EDF, E.ON, SSE and Scottish Power [27].

Much of the debate around the economic potential of DR has been focusing on the actual benefits of DR for consumers. The Department of Business, Enterprise and Regulatory Reform commissioned a Cost-Benefit Analysis on the economic impacts of smart meters. The study was undertaken by consultants and was concluded at the end of 2008. At the time of writing of this paper Government is still considering the results of the consultant's Cost-Benefit Analysis. In particular, there is disagreement around the assumed costs of smart meters. Some business corporations have already commented that the Cost-Benefit Analysis exaggerates the costs of smart meters, hence ruling out some potentially profitable roll-out options. Consumer benefits and potential carbon savings from DR assumed in the Cost-Benefit Analysis study are also sources of controversy. The consultant's report estimates the cost of roll-out at a total 
of $£ 14$ bn against industry projections of $£ 8 b n$, reflecting a cautious approach to such economic studies which is required by the UK Treasury.

The study itself compromised five technology specifications (a minimum meter specification; 'smart enabled' meters that substitute old meters; dumb meters combined with smart boxes; retrofit devices, which are either clamped, fastened or glued on to meters; and clip-on customer display units) combined with five roll-out options (giving regional franchisees the responsibility for the roll-out; leaving the rollout to the market; leaving the roll-out to the market after eight - market tipping pointor seven years - fast market tipping point; leaving it to the market with a mandate to renew and replace installations). Some of the most advanced smart metering options present irrecoverable Net Present Values. For instance, the Net Present Values associated with 'smart enabled' meters have negative values when combined with the market roll-out option, estimated at -804 million British Pounds (equivalent to - \$ 1.1 billion in 2007 dollar value). The minimum meter specification is also characterised by negative Net Present Values. When combined with the regional franchise roll-out option its Net Present Value is estimated at -4497 million British Pounds (equivalent to - $\$ 6.16$ billion in 2007 dollar value). Dumb smart meters, on the contrary, present positive Net Present Values regardless of which roll out options they are combined with.

One problem with Cost-Benefit Analyses of smart meters is that they fall short of estimating the potentially wider impacts of innovation [28]. Most Cost-Benefit Analyses rely upon the evidence provided by pilot roll-out cases showing that - when fully informed - consumers tend to respond to higher energy prices [29]. However, the complete long-term economic benefits and societal impacts of new information systems remain uncharted.

\subsubsection{Attempts to foster DR at UK policy level}

DR has recently gained significant momentum at policy level. During the Report Stage of a new legislative package - the Energy Bill - on $29^{\text {th }}$ October 2008 Lord Hunt of Kings Heath, said [30]: 
"I am pleased to announce that the Government has taken the decision to mandate smart meters for all households. This is a major step forward; no other country in the world has moved to an electricity and gas smart meter roll-out on this scale. The existing powers in the Energy Bill will enable the Government to proceed with a domestic roll-out."

Although the roll-out of smart meters is likely to revolutionise DR in the UK, its policy success is not surprising in a panorama where both the Prime Minister and the leader of the opposition seek increased consumer participation in both electricity and gas markets. For instance, in a speech on climate change in November 2007 The Prime Minister said:

"For every household - over the next decade, there will be the offer of a smart meter that will allow two way communication between the supplier and customer - giving more accurate bills and making it easier for people to generate their own energy through microgeneration and sell it onto the grid."

The path which led to current policy thinking has been rather long. Already in a 2007 Energy Policy White Paper the British Government stated that electricity display monitors should be provided with all new and replacement meters and should be sent to all customers who requested one. The evidence on which decisions on smart-meter roll-out and, hence, the future of DR in the UK will be taken is to be based on historical consumption data to be provided on all domestic customers' electricity and gas bills and statements; provision of real-time display devices to particular customer segments by electricity suppliers; provision of smart meters to all business customers above a certain usage threshold by electricity and gas suppliers by 2013; and completion of economic assessment work and consultation to finalise the policy position in respect of smart metering for small businesses and domestic consumers.

\subsection{Italy}

When looking at DR in Italy, most of the literature has been devoted to smart metering. With about $90 \%$ of overall meters already installed, Italy is the European country with the highest penetration of advanced electricity meters. Besides this particular DR infrastructure, there are other aspects which are worth focusing on. This section (i) examines some DR programmes in place in Italy; (ii) describes the 
estimated potential of DR in Italy and (iii) policy-makers' attempts to foster DR in the market.

\subsubsection{DR programmes in Italy}

Interruptible Programmes represent 6.5\% of peak power and Load Shedding Programmes initiate automatic load shedding in emergency situations [31]. With Interruptible Programmes participants are required to reduce their load to predefined values. With Load Shedding Programmes utilities have the possibility to remotely shut down participants' equipment at short notice. One significant difference between these two programmes is that for Interruptible Programmes participants who do not respond can face penalties.

Interruptible Programmes are applied to very large industries only. Until 2007 their official remuneration was determined by a decision of the energy authority [32]. However, one could infer that these compensations were forms of state subsidies to sectors facing economic difficulties. For instance, the price of remuneration for 2007 consisted of a fixed lump sum of $150,000 € / \mathrm{MW} /$ year (equivalent to $\$ 189,247$ in 2007 dollar value) for a number of 10 interruptions plus 3,000 €/MW (equivalent to $\$$ 3643 in 2007 dollar value) for each additional interruption actually incurred throughout the year. This price was defined without the analytical support of any Cost-Benefit Analysis or Impact Assessment. However the price of remuneration is about three times higher than the yearly benefit for interruptions, even taking into account a $20 \%$ generator capacity margin over peak times to ensure supply security. Since 2008 the Italian TSO (Terna) selects the resources for interruptions.

Load Shedding Programmes are divided into real time programmes (without notice) and 15 minute notice programmes. The size ranges from $1200 \mathrm{MW}$ for real time programmes to $1750 \mathrm{MW}$ for notice programmes. Participants in these programmes have to install and maintain Load Shedding Peripheral Units and will be compensated according to a non-market price defined in regulation. The size of curtailable power is of $10 \mathrm{MW}$ for programmes without notice and $3 \mathrm{MW}$ for programmes with notice.

Italy has also used Time of Use rates for several years. In the past Italy has experienced significant time variations of cost for electricity supply. Part of the 
potential associated with shifting loads to hours of low price has been put into action by many industries to obtain the most convenient hourly profiles. Emergency situations with little price spikes emerging from the market have been dealt in the past with regulated measures, e.g. with about $3000 \mathrm{MW}$ of interruptible loads. More recently, Italy has been moving towards peak/off peak prices to eligible customers as described in section 4.3.3.

\subsubsection{Estimating DR potential in Italy}

With 48570 GWh imported in 2007 against 2640 GWh exported in the same year [33], and with retail prices amongst the highest in the Euro area, in Italy the need for reducing marginal cost of generation and rendering demand flexible to peak prices is evident.

At research level, an analytical effort to measure DR potential has been produced by CESI [34]. They carried out a study based on the Market Potential Calculator developed by IEA-DSM, taking into account estimates of customer participation in DR programmes. The technical and economic potential estimates also consider other countries' experiences. The CESI study concludes that the Italian DR technical and economic potential ranges between $1.6 \%$ and $4.2 \%$ in relation to peak power. This estimate highlights that there are two classes of consumption that could be subject to DR plans for reducing demand. On the one side, air conditioners and water heaters for residential and commercial users could be applied to Direct Load Control actions associated with critical peak tariffs. On the other side, large industrial customers in addition to existing Interruptible Services could be associated with critical peak tariffs and Demand Side Bidding.

An additional potential consists of back-up generators on which to date no official survey has been carried out. Notwithstanding some (e.g. environmental) constraints, such generators could be used for a higher number of hours per year than at present, allowing industrial sites to reduce their intake from the grid at times of higher loads. For the system, the use of back-up generators would represent a resource corresponding to a net load reduction. 


\subsubsection{Attempts to foster DR at policy level in Italy}

At policy level, the energy regulator (Autorità per l'energia elettrica e il gas) has recently introduced a new mechanism for calculating the price of energy with the aim of shifting consumption to periods of lower and cheaper loads [35]. The new pricing system will apply to all those end-users in possession of electronic meters; this represents almost $90 \%$ of Italian customers and will become the totality in the next three years. After one year of gradual implementation, the new mechanism will be fully in place in 2010. There will be two tariffs: a more expensive one from 08:00 in the morning to 19:00 in the evening Monday to Friday and a cheaper one for any other time.

\subsection{Spain}

It has been observed that growth in wind power might be the main driver for DR programmes in Spain [36]. Whether this is the correct explanation or not, there are two wide categories of DR programmes in place in Spain: system-led and price-led programmes.

\subsubsection{DR programmes in Spain}

System-led programmes are shifting from classical to market-grounded programmes. For instance, Direct Load Control has been in place for about 20 years and is about to give way to ancillary services. Since 1988 a number of large industrial consumers (about 200 industries with a demand over $5 \mathrm{MW}$ ) have been able to choose special tariffs voluntarily. The Spanish TSO, Red Eléctrica de España, can request these industries to limit the demand during periods of time varying from 45 minutes to 12 hours, upon the condition that the TSO informs industrial consumers in advance. The yearly maximum number of hours and requests of demand reductions by the TSO is defined in advance for each end-user. Each year industrial consumers receive a discount both in fixed and variable charges according to number of requests to reduce their demand.

Red Eléctrica de España is supposed to use these Direct Load Control mechanisms when there are physical imbalances between supply and demand. The Industry 
Ministry must explain and justify the reasons for demand reductions every time these are requested to end-users. The European Transmission System Operator (ETSO) reports that the yearly number of days when the Spanish TSO has requested demand reductions has been varying between 0 to 4 days [37]. Exceptionally, in 2001 demand reductions were requested during 10 days. The ad hoc tariffs for large industrial consumers will soon cease to exist. Red Eléctrica de España is discussing with the industry how to use these resources within a wider market for ancillary service provision [38] in which market participants will be able to bid on load curtailment in the spot market as operating reserve. This means that if their bids are accepted, participants are paid the spot market energy price whenever load curtailment is required [39]. Since 2002 an Interruption Flexible Management Programme has been developed by Red Eléctrica de España, which manages most of the transmission network in Spain. It estimates total interruption capacity of the system at around 2600MW. The instant interruption capacity is considered greater than 1000MW.

Price-led programmes have been in place for some time, with time-of-use tariffs providing economic signals for demand response [40]. With the aim of dissuading industrial customers from using electricity during peak hours, hence increasing the demand and energy cost components of their electricity bills, the TSO has the right to determine the hours of operation for the period corresponding to the most expensive period of the year. The time-of-use rates are based on dividing the 8760 hours in a year into seven time-of-use periods. For each period, there is a contracted demand level and a different rate for each of the demand and energy components of the tariff. Every year the TSO reviews rates for each time-of-use period. Table 2 shows the time of use rates applied in 2005 .

Table 2- Spanish time-of-use tariffs: rates for the demand and energy components-year 2005 [41]

Interestingly, a study which was commissioned on the basis of a Spanish Royal Decree (2392/2004) and looking at 87 large customers making use of time-of-use tariffs in 1994, revealed that for industrial customers reducing production to make savings on their electricity bill was ultimately not profitable. Financial losses through reduced production were considered to be greater than the decrease in their electricity 
bills during peak time (Period 1 in Table 3). Also, it should be highlighted that the choice of time-of-use tariffs is in practice limited to those consumers who decide to move away from the incumbent utility. This is often an economically unfavourable decision in Spain as there are times when the regulated supply tariff is lower than the market price.

\subsubsection{Estimating DR potential in Spain}

Perhaps one of the biggest projects carried out in Spain to create the basis for DR initiatives is called INDEL. It was initiated in 1988 with Government funding with the overall aim of expanding the knowledge on the behaviour of the demand side. As one of its main outputs, the INDEL project estimated the system demand at any hour by consumption of 8 large segments of consumers representing $51 \%$ of maximum demanded electricity [42]. As part of spin-off projects it has become possible to identify some of the salient features of the Spanish demand, notably that it has relatively high peaks but also considerable variability in consumer behaviour. As a result, considerable risks have been identified for implementation of DR programmes in Spain. These include (i) high degree of variability of consumers' response; (ii) high dispersion of consumers' response in the grid; and (iii) difficulties in guaranteeing permanence with reduction offers in the medium and long term [43].

Attempts to overcome these risks have been based on a number of DR studies, programmes and technologies. For instance, a recent study carried out by the Instituto de Ingenieria Energética has tried to develop methodologies to determine the potential of demand management for large consumers of electricity [44]. The study is based on a survey of large industrial consumers, i.e. car industries, fish farms, airports and train builders. One of the main findings was that the weight of manageable power in relation to the contracted power is frequently high (22\% for car industries, $96 \%$ for fish farms and airports and $81 \%$ for train builders). Consequently, load forecasts have been developed on the bases of medium and long term projections of economic growth rate, population growth and the impact of energy efficiency policies and Load Management, in order to predict reductions of peak load growth and changes in the load duration curve. 
DR technologies in Spain involve consumer management tools to organise and store information about Spanish interruptible tariff consumers. These comprise (i) planning and valuation applications which allow tracking of the evolution of consumers for the last ten years; (ii) consumer directory, negotiation and planning tools for monitoring and analysing consumers using static data (e.g. contract type, supply type) and dynamic data (e.g. consumption and load profiles); and (iii) prototypes for assisting the interruption system operation, in the form of forecast models of consumer response during the operation period.

\subsubsection{Attempts to foster DR at policy level in Spain}

In 2007 the Spanish Government established a rollout timetable that foresees the replacement of old meters with electronic smart meters with remote metering capabilities by 2018 [45].

\section{CONCLUSIONS}

Besides the engagement of major energy users in system balancing, the presence of DR in European electricity markets has been traditionally low. It has been observed that customers lack means and a limited number of incentives are in place to respond to changes in prices [46]. A few factors undermine effective DR in Europe: the lack of real-time price information reaching consumers; regulated retail prices in some countries; out-dated metering technologies; system operators focused on supply side resources; and an approach traditionally averse to DR [47]. However, things seem to be rapidly evolving especially under the European Commission's objectives of strengthening energy efficiency, mitigating green house gas emissions and promoting renewable sources of energy. Current developments within Europe point to a wide rollout of smart metering technology, which ideally will create the platform for an informed consumer capable of responding to prompts from the supply side. Although DR in Europe has not realised its full potential yet, prospects for the future are brighter.

The paper has considered programmes already in place in some Member States of the European Union. Currently, DR programmes focus mainly on industry, as most European utilities include Direct Load Control programmes as part of their DSM 
strategies, with fixed compensations attributed to small numbers of large industrial end-users. Interruptible Programmes for large industries are very frequent, although the mechanisms for compensating industries vary significantly. The extent to which such system-led programmes can be labelled as authentic DR initiatives is debatable. In the future however, large numbers of end-users, including commercial customers and households could be involved in DR programmes with compensations consisting of prices and deliberate shifts in electricity demand in correspondence with peak loads.

From the review of some of the studies exploring the economic and technological potential of demand side response it is clear that the potential of DR in Europe varies from country to country. The estimated penetration level of DR technologies; the amount of industrial manageable power; the household load curves all differ substantially across Europe. The commonalities highlighted by research studies regard (i) the low level of DR in European countries in recent years; (ii) the increase in load management forecasts (at least in continental Europe); (iii) the prevalence of interruptible programmes; and (iv) the absence of DR in system and network planning.

Until a couple of years ago, DR initiatives were largely neglected at policy level. There are at least five reasons why it took time for DR to make an impact among policy-makers. Firstly, while it is clear what DR initiatives - e.g. time of use tariffs can achieve in terms of demand shifting from peak periods, limited knowledge has been developed about its overall energy saving capacities. Secondly, the cost estimates for DR technologies and infrastructure have decreased in recent years, but remain significantly high: some European countries hesitated to invest because they were expecting increases in volumes and reduced marginal costs. Thirdly, DR does not represent a panacea solution for all energy-related problems, including climate change and security of supply: EU policy-makers are still searching for the right mix of solutions that will facilitate reaching their ambitious environmental goals. Fourthly, to date there has not been a strong policy push for DR because the focus has been on liberalising markets. Finally, some of the most recent EU policy proposals seem to indicate that there might be a policy change if DR demonstrates its full potential, highlighting that uncertainty about DR performance and prospects has held back more 
aggressive policy, and underlining the significance of current demonstration programmes.

A clear indication of a change in gear for policy support of DR is represented at national level by smart meters and at the EU level by the attempt to ensure equilibrium between power supply and demand through encouraging Member States to provide information on energy efficiency mechanisms as well as price signals, feed-back on annual consumption and better billing. The recent and ongoing roll-out of smart meters in several European countries means that soon there will be the technological sine qua non conditions for DR. Some 12 EU Member States are currently either implementing or discussing policy plans for smart meter roll-out. Much of the discussion in these countries has moved from whether investments should be made to how investments should occur [48].

\section{ACKNOWLEDGMENTS}

The research leading to this paper was conducted as part of both the EPSRC/E.On supported Transitions project and the EPSRC supported Supergen FlexNet project.

\section{REFERENCES}

[1] Leach M, Bilton M, Ramsay C, Devine Wright H, Johnstone C, Kirschen D (2007), "Demand Side Management" in Delivering a Low Carbon Electricity System: Technologies, Economics and Policy, Grubb, Jamasb and Pollitt (eds.), Cambridge University Press.

[2] Faruqui A. and S. George (2005), Quantifying Customer Response to Dynamic Pricing, Electricity Journal, 18(4), 53-63.

[3] Gallant, R. and R. Koenker (1984), Costs and benefits of peak-load pricing of electricity: a continuous-time econometric approach, Journal of Econometrics, 26 (1-2), 83-113.

[4] Spees, K. and L. Lave (2007),.Demand Response and Electricity Market Efficiency, Electricity Journal, vol. 20 (3), 69-85.

[5] Owen, J. and J. Ward, (2007), Smart meters in Great Britain: the next steps? Sustainability First. Energy Policy, 36 (12), 484-489.

[6] Directive 96/92/EC, 1996, of the European Parliament and of the Council of Dec. 19, 1996, concerning common rules for the internal market in electricity, OFFICIAL J. OF EUROPEAN UNION, 1997, L27, at 20-29, and Directive 2003/54/EC, 2003, of the European Parliament and of the Council of June 26, 2003, concerning common rules 
for the internal market in electricity and repealing Directive 96/92/EC, OFFICIAL J. OF EUROPEAN UNION, L176, 2004, 37-55.

[7] M.M. Roggenkamp and F. Boisseleau (2005). The Liberalization of the EU Electricity Market and the Role of Power Exchanges, THE REGULATION OF POWER EXCHANGES IN EUROPE, Energy \& Law series.

[8] European Commission (2007), Explanatory Memorandum - legislative package on the internal market for electricity and gas, COM (2007).

[9] Torriti, J. (2008), Does the Impact Assessment on the 'Third Package' provide the correct economic forecast for the liberalisation of the EU energy markets? EUI Working Paper (Florence: European University Institute).

[10] EEA (European Environment Agency), 2006, Energy and environment in the European Union. Tracking progress towards integration, EEA Report No. 8/2006, Copenhagen.

[11] Enerdata (2008), World Energy Demand in 2007. www.enerdata.fr.

[12] IEA (2008), Energy Policy Reviews: The European Union.

[13] Papagiannins, G. et al (2008), 'Economic and environmental impacts from the implementation of an intelligent demand side management system at the European level' Energy Policy, 36, 163-180.

[14] Capgemini (2008), Demand Response: a decisive breakthrough for Europe.

[15] Directive concerning measures to safeguard security of electricity supply and infrastructure investment, OJ L 33 of 4 February 2006.

[16] "Communication on a first assessment of National Energy Efficiency Action Plans", COM (2006) 545.

[17] Directive 2006/32/EC on Energy End-Use Efficiency and Energy Services.

[18] UKERC (2006), An Assessment of the Evidence on the costs and impacts of intermittent generation on the British electricity network, UK Energy Research Centre, London, http://www.ukerc.ac.uk/Downloads/PDF/06/0604Intermittency/0604IntermittencyRepo rt.pdf

[19] Turvey, R., (2003), "Ensuring adequate generation capacity," Utilities Policy, Elsevier, $11(2), 95-102$.

[20] VTT (2006), Demand response activities in Finland, DR Workshop Copenhagen, 13 November 2006.

[21] Siderius, P.J.S., E. Leussink, P. Nonhebel (2004), Scan vraagrespons kleinverbruikers elektriciteit, (Utrecht: SenterNovem).

[22] Vasconcelos, J. (2008), Survey of Regulatory and Technical Development Concerning Smart Metering in the European Union electricity market (Florence School of Regulation RSCAS Policy Paper: 2008/01). 
[23] Vasconcelos, J. (2008), Survey of Regulatory and Technical Development Concerning Smart Metering in the European Union electricity market (Florence School of Regulation RSCAS Policy Paper: 2008/01).

[24] Anderssen et al (2006), Analyses of Demand Response in Denmark, Ris $\varnothing$, RAM-løse edb, (Copenhagen: Ea Energy Analyses).

[25] DTI (2002), The Energy Review: a Performance and Innovation Unit Report (London: Department of Trade and Industry).

[26] Ofgem (2003) "Vigorous Competition for domestic customers, but Ofgem remains vigilant", Press Release, 16 June 2003.

[27] Ofgem (2008), Energy Demand Research Project - Review of Progress.

[28] Brophy, A., Tooraj J. and M. Pollitt (2009), Smart Metering and Electricity Demand: Technology, Economics and International Experience, EPRG Working Paper EPRG0903 (Cambridge: Working Paper in Economics).

[29] Imperial College (2008), Response to Ofgem's consultation on Domestic Metering Innovation

http://www.ofgem.gov.uk/MARKETS/RETMKTS/METRNG/SMART/Documents1/1 3357-Imperial Centre response.pdf.

[30] Energy Retail Association (2008), Report Stage of the Energy Bill by Lord Hunt of Kings Heath, Press Release http://www.energyretail.org.uk/media/press/2008/ERASmartMetermandateOct08.html

[31] Grattieri, W. (2006) Demand Side Management priorities in Italy Proceedings of Load Management \& Demand Response Programmes 2006 London, 2nd \& 3rd February 2006.

[32] Decision n. 289/06: "Disposizioni per l'approvvigionamento e la remunerazione delle risorse in grado di garantire l'interrompibilità istantanea o con preavviso dei prelievi di energia elettrica a decorrere dall'1 gennaio 2007" http://www.autorita.energia.it/docs/06/289-06.htm.

[33] Energy Information Administration (2007), International Energy Annual.

[34] CESI (2005), Metodi e strumenti per la modulazione della domanda Rapporto A5021621.

[35] Decision ARG/elt 56/08: "Disposizioni in materia di applicazione delle condizioni economiche del servizio di maggior tutela (corrispettivi PED), di obblighi di registrazione e di messa a disposizione dei dati di prelievo e conseguente adeguamento di TIV e TILP”.

[36] Capgemini (2008), Demand Response: a decisive breakthrough for Europe.

[37] European Transmission System Operator (2007), Demand Response as a resource for the adequacy and operational reliability of the power systems Explanatory Note.

[38] REE (2005), Desarrollo de gestion de demanda orientada a la eficiencia conjunta de los procesos suministro-consumo de la electricidad II Foro de Madrid sobre DSO. 
[39] REE (2005), Desarrollo de gestion de demanda orientada a la eficiencia conjunta de los procesos suministro-consumo de la electricidad II Foro de Madrid sobre DSO .

[40] Lijesen, M.G. (2007), The real-time price elasticity of electricity, Energy Economics, 29, 249-258.

[41] Álvarez, A. Gabaldón and A. Molina (2004), "Assessment and Simulation of the Responsive Demand Potential in End-User facilities: Application to a University Customer". IEEE Trans. on Power Systems, 19, 1223-1231.

[42] Pérez-Arriaga, I. (2002), "Estructura y organización del sector eléctrico español”, internal report to the Comisión Nacional de Energía, www.cne.es

[43] Sánchez-Tembleque, L., Pérez-Arriaga, I., M. Pardo (2005), "Electric load management", report for Fundación Alternativas.

[44] REE (2005), Desarrollo de gestion de demanda orientada a la eficiencia conjunta de los procesos suministro-consumo de la electricidad II Foro de Madrid sobre DSO

[45] Ministerio de Industria, Turismo y Comercio, REAL DECRETO 1110/2007, de 24 de agosto, porel que se aprueba el Reglamento unificado de puntos de medida del sistema eléctrico.

[46] Vasconcelos, J. (2008), Survey of Regulatory and Technical Development Concerning Smart Metering in the European Union electricity market (Florence School of Regulation RSCAS Policy Paper: 2008/01).

[47] IEA (2003), The power to choose - demand response in liberalized electricity markets.

[48] Owen, J. and J. Ward, (2007), Smart meters in Great Britain: the next steps? (London: Sustainability First).

\section{TABLES}

Table 1-Demand Response forecast in UCTE countries (GW)

\begin{tabular}{|l|l|l|l|l|l|}
\hline Country & $\mathbf{2 0 0 8}$ & $\mathbf{2 0 1 0}$ & $\mathbf{2 0 1 3}$ & $\mathbf{2 0 1 5}$ & $\mathbf{2 0 2 0}$ \\
\hline Italy & 4.00 & 4.00 & 4.00 & 4.00 & 4.00 \\
\hline France & 3.60 & 3.00 & 3.00 & 3.00 & 3.00 \\
\hline Spain & 2.00 & 2.30 & 2.50 & 2.70 & 3.00 \\
\hline Netherlands & 1.00 & 1.00 & 1.10 & 1.25 & 1.50 \\
\hline Greece & 0.40 & 0.60 & 0.80 & 1.00 & 1.30 \\
\hline Germany & 0.20 & 0.30 & 0.40 & 0.50 & 0.05 \\
\hline Belgium & 0.20 & 0.20 & 0.20 & 0.20 & 0.20 \\
\hline Hungary & 0.00 & 0.05 & 0.08 & 0.10 & 0.20 \\
\hline Montenegro & 0.03 & 0.03 & 0.05 & 0.05 & 0.05 \\
\hline Luxemburg & 0.02 & 0.02 & 0.02 & 0.02 & 0.02 \\
\hline UCTE & 11.45 & 11.50 & 12.15 & 12.82 & 13.32 \\
\hline
\end{tabular}




\begin{tabular}{|l|l|l|l|l|l|}
\hline countries & & & & & \\
\hline
\end{tabular}

Table 2 - Spanish time-of-use tariffs: rates for the demand and energy components-year 2005 (Source: REE, 2005)

\begin{tabular}{|l|l|l|l|l|l|l|c|}
\hline Component & Period 1 & Period 2 & Period 3 & Period 4 & Period 5 & Period 6 & Period 7 \\
\hline $\begin{array}{l}\text { Demand } \\
\text { (EUR/kW/year) }\end{array}$ & 31.712734 & 21.137602 & 18.118851 & 12.682563 & 12.682563 & 12.682563 & 9.752409 \\
\hline $\begin{array}{l}\text { Energy } \\
\text { (EUR/kWh) }\end{array}$ & 0.177518 & 0.061463 & 0.061641 & 0.055122 & 0.0362 & 0.023543 & 0.018543 \\
\hline
\end{tabular}

